\title{
PEDAGOGO NO PROEJA: IDENTIDADE E SABERES
}

\author{
LuCiane Serrate Pacheto Bacheti ${ }^{1}$, Alex Jordane de Oliveira ${ }^{2}$ \\ Pós-graduação Lato Sensu em PROEJA, Instituto Federal do Espírito Santo \\ E-mail: lucianesp@ifes.edu.br, alex.jordane@gmail.com
}

\section{RESUMO}

O presente trabalho surge da necessidade de compreender como os pedagogos que atuam nos cursos do Programa Nacional de Integração da Educação Profissional com a Educação Básica na modalidade de Educação de Jovens e Adultos - PROEJA constroem a sua identidade. Assim, investigaram-se as práticas pedagógicas desenvolvidas pelos pedagogos nos cursos de PROEJA nos campi do Instituto Federal do Espírito Santo: Vitória, Colatina e Itapina. O caminho trilhado para a realização do estudo deu-se a partir da pesquisa qualitativa. Aplicou-se questionário à equipe docente do PROEJA e entrevistaram-se coordenadoras e pedagogas do PROEJA nos campi pesquisados. Organizaram-se os dados em três categorias: aspectos pedagógicos, operacionais e subjetivos, considerando a atuação do pedagogo, os desafios enfrentados por ele e as demandas trazidas a ele. A consolidação dos dados coletados demonstrou que a grande maioria dos professores, no dia a dia da escola, busca o pedagogo para apoio nos aspectos pedagógicos, seguidos dos aspectos subjetivos. A investigação apontou como fundamental e necessária a formação continuada, tanto dos docentes quanto do pedagogo, realizada por meio de pesquisa em cursos de pós-graduação, ao longo do próprio exercício profissional, em espaços intencionalizados e sistematizados de formação em serviço. Assim, diante da complexidade das práticas educativas, em especial aquelas realizadas no PROEJA, a identidade do pedagogo é construída e reconstruída, permanentemente, dentro do processo dinâmico característico da educação e da própria vida, num eterno vir a ser e estar sendo.

Palavras-chaves: PROEJA; pedagogo; identidade; formação de professores.

\section{INTRODUÇ̃̃o}

O desejo de realizar este trabalho nasceu de inquietações adquiridas na prática cotidiana da função pedagógica, desde setembro de 2008, no Curso Técnico em Mecânica nas modalidades Integrado e Concomitante ao Ensino Médio, no Instituto Federal do Espírito Santo campus São Mateus. Recentemente, a implantação de cursos de formação inicial do Programa Nacional de Integração da Educação Profissional com a Educação Básica na Modalidade de Educação de Jovens e Adultos/Formação Inicial e Continuada - PROEJA/FIC, na instituição, levou-nos a refletir sobre o papel do pedagogo nesse programa. Foi a partir dessa reflexão que nos sentimos provocados a entender melhor como o pedagogo se constitui como profissional e que saberes ele precisa mobilizar na sua prática diária.

Assim, investigamos as práticas pedagógicas desenvolvidas pelos pedagogos, nos cursos de PROEJA, nos campi do Instituto Federal do Espírito Santo em Vitória, em Colatina e em Itapina, na tentativa de responder à seguinte questão: como os pedagogos que atuam nos cursos do PROEJA constroem a sua identidade?

Fundamentamos esta pesquisa à luz de documentos oficiais que tratam da formação desse profissional, da legislação do PROEJA e das concepções dos seguintes autores: Maurice Tardif e Paulo Freire que discutem os saberes necessários á prática educativa e de Selma Garrido Pimenta - que estuda a identidade do pedagogo no Brasil. Esta defende:

[...] a necessidade de a escola pública contar nos seus quadros com especialistas (pedagogos) que desempenhem a mediação entre a organização escolar e o trabalho docente de modo a garantir as condições favoráveis à consecução dos objetivos pedagógico-políticos da

\footnotetext{
${ }^{1}$ Graduada em Pedagogia pela Universidade Federal do Espírito Santo e pós-graduanda do Curso de Pós-Graduação LATO SENSU em Educação Profissional Técnica Integrada à Educação Básica na modalidade de jovens e adultos / PROEJA/ Instituto Federal do Espírito Santo - Campus São Mateus

${ }^{2}$ Mestre em Educação pela Universidade Federal de Minas Gerais e Doutorando pelo Programa de Pós-Graduação em Educação da Universidade Federal do Espírito Santo.
} 
educação escolar (PIMENTA, 2002, p.186).

Na concepção de Pimenta (2006), a Pedagogia é mais ampla do que a docência, sem pretender com isso diminuir a importância da docência. Assim expressa a autora:

[...] pensamos que a identificação do pedagogo com o docente incorre num equívoco lógicoconceitual. A Pedagogia é uma reflexão teórica a partir e sobre as práticas educativas. Ela investiga os objetivos sociopolíticos e os meios organizativos e metodológicos de viabilizar os processos formativos em contextos socioculturais específicos. [...] Não é possível mais afirmar que o trabalho pedagógico se reduz ao trabalho docente nas escolas. A ação pedagógica não se resume a ações docentes, de modo que, se todo trabalho docente é trabalho pedagógico, nem todo trabalho pedagógico é trabalho docente (PIMENTA, 2006, p. 29).

O momento atual, caracterizado pela expansão da Rede de Educação Profissional e Tecnológica em todo país, oferece-nos terreno fértil para discutir mais profundamente as especificidades do PROEJA. Nesse sentido, é preciso formar trabalhadores que respondam aos desafios colocados pela sociedade atual, não apenas no que diz respeito à competência laboral, mas também à capacidade de, criticamente, ler, ser e estar no mundo e, ainda, comungando com este, transformá-lo, segundo Freire (1989). Tudo isso exige um processo educativo que considere o ser humano nos diversos aspectos que o totalizam (social, cultural, afetivo, etc.), sendo necessário, para tanto, romper com a lógica do ensino puramente tecnicista, em que apenas a transmissão do conhecimento técnico é priorizada.

Na perspectiva de formação para o PROEJA os profissionais da educação, especialmente aqueles que atuam nesse programa, precisam estar cientes de suas necessidades de formação permanente, haja vista as especificidades que a modalidade demanda. Além disso, devem se preocupar em construir junto com jovens e adultos uma vivência educacional com eles e para eles, com aprendizagens significativas, constantes para ambos. Freire pontua a respeito disso o seguinte:

[...] a conscientização é "natural" ao ser que inacabado, se sabe inacabado. [...] Mais ainda, a inconclusão que se reconhece a si mesma, implica necessariamente a inserção do sujeito inacabado num permanente processo social de busca. Históricos-sócio-culturais, mulheres e homens nos tornamos seres em que a curiosidade [...] se torna fundante da produção do conhecimento (FREIRE, 2002, P.23).

Dessa forma, é preciso identificar que saberes precisam ser mobilizados pelos profissionais envolvidos na árdua tarefa de inclusão desse público. Segundo Tardif (2005) o saber docente é um saber plural e constituído por diferentes perspectivas. O autor organiza esses saberes em cinco grupos: saberes da formação profissional (construídos pelas instituições de formação de professores); da ação pedagógica (provenientes de reflexões sobre a prática educativa no sentido amplo do termo e de orientação da atividade educativa); disciplinares (que emergem da tradição cultural); curriculares (advindos de programas escolares) e saberes experienciais (adquiridos no cotidiano).

Assim, educadores e educandos produzem o conhecimento na complexa teia de relações que estabelecem entre si no interior da escola. O autor destaca:

[...] os próprios professores, no exercício de suas funções e na prática de sua profissão, desenvolvem saberes específicos, baseados em seu trabalho cotidiano e no conhecimento do seu meio. Esses saberes brotam da experiência e são por ela validados. Eles incorporam-se à experiência individual e coletiva sob a forma de habitus e habilidades, de saber-fazer e de saber ser (TARDIF, 2005, p.38-39).

Podemos concluir que a referência de educador é aquele que consegue articular- se bem entre os diferentes saberes: da formação profissional, da ação pedagógica, disciplinares, curriculares e experienciais. E o pedagogo, como se insere nesse contexto? Que saberes ele precisa dominar para atender a essa demanda emergente. 


\section{METODOLOGIA}

O caminho trilhado para a realização do estudo deu-se a partir do enfoque da pesquisa qualitativa, que se caracteriza por buscar compreender e classificar um determinado fenômeno social (OLIVEIRA, 1983 apud GIL,1995) com o que a pesquisa se afina.

Para colher as informações, optou-se pela aplicação de questionários aos docentes e por entrevistas com as gestoras do programa nos campi pesquisados. $O$ questionário foi aplicado a 14 professores que atuam no PROEJA. Ele foi estruturado com 14 questões, sendo cinco referentes a dados pessoais, de formação e profissionais dos docentes; cinco referentes ao relacionamento interpessoal e profissional; uma questão abordando a importância desse programa na escola. Este instrumento de pesquisa contou ainda com mais três questões, sendo duas direcionadas à atuação do pedagogo e uma para a própria atuação do professor, com o objetivo de traçar o perfil da equipe docente e levantar sua opinião sobre o trabalho realizado pelo pedagogo.

As entrevistas foram realizadas com uma diretora de desenvolvimento educacional; uma gerente de gestão educacional; três coordenadoras de cursos (uma das coordenadoras é uma pedagoga que acumula essa função) e três pedagogas dos cursos técnicos do PROEJA nos campi Colatina, Itapina e Vitória. As entrevistas se focaram na organização do PROEJA nesses campi, nos desafios enfrentados, nas atividades desenvolvidas pelo pedagogo e na interação entre esses profissionais. O objetivo foi o mapeamento dos diversos olhares sobre a atuação desse profissional: o pedagogo sob o olhar da equipe docente do PROEJA, sob o olhar dos coordenadores de curso e o olhar do pedagogo sobre si mesmo, suas práticas cotidianas. As entrevistas incluíram quatro questões que trataram dos dados pessoais e de formação das entrevistandas, quatro questões referentes às interações entre as equipes e quatro questões sobre o PROEJA e a atuação do pedagogo.

Para facilitar a análise, organizaram-se os dados em três categorias surgidas por meio de uma pesquisa piloto realizada, a partir de práticas cotidianas no exercício pedagógico do Curso Técnico em Mecânica, em parceria com a pedagoga do Curso Técnico em Eletrotécnica do campus São Mateus do Ifes e com uma professora da Rede Municipal de Ensino de São Mateus. Esse piloto teve como objetivo tentar responder qual o papel do pedagogo dentro das instituições de educação profissional, investigando o que os professores esperavam do trabalho do pedagogo nessas instituições e quais demandas os levavam, de fato, a procurá-lo durante seu trabalho diário.

A análise dos dados nos levou a categorizá-los em três grupos: aspectos pedagógicos - que tratam das atividades pedagógicas propriamente ditas (planejamento, avaliação, metodologia, entre outras); aspectos operacionais - referentes às atividades administrativas (preenchimento de pautas, orientações sobre normas, etc.) e aspectos subjetivos - que dizem respeito aos assuntos referentes a comportamentos, frequência, motivação dos alunos.

\section{RESULTADOS/DisCUSSÃo}

Os dados foram analisados a partir das três categorias definidas anteriormente no piloto da pesquisa, sendo: (a) Aspectos Pedagógicos - que tratam das atividades pedagógicas propriamente ditas; (b) Aspectos Operacionais - que tratam das atividades administrativas e (c) Aspectos Subjetivos - que dizem respeito aos assuntos relativos ao comportamento e atitudes dos alunos.

A análise dos questionários aplicados aos 14 professores é apresentada como análise dos resultados $\mathrm{A}$. E a análise da entrevistas com as gestoras do PROEJA nos campi pesquisados é apresentada como análise dos resultados $B$.

\section{Análise dos Resultados A: Questionários}

Dos 14 professores que responderam ao questionário, 10 ministram componentes curriculares da formação geral e complementar (língua portuguesa, biologia, história, geografia, matemática, química, física e artes) e quatro, os componentes curriculares referentes à área técnica (informática, fundamentos da construção civil, desenho auxiliado por computador, desenho técnico, gestão de segurança).

\section{Perfil da equipe docente do PROEJA}

Para traçar o perfil da equipe docente que trabalha no PROEJA foram coletados dados sobre gênero, idade, formação, tempo de formação, tempo de atuação no magistério, tempo de atuação em PROEJA/EJA e componente curricular ministrado atualmente. 
Da equipe docente do PROEJA nos campi pesquisados que responderam ao questionário 35,7\% são mulheres (cinco professoras) com idade entre 24 e 49 anos, dentre as quais três são graduadas, uma pósgraduada e outra com mestra em educação; três delas têm menos de 10 anos de formadas. $E$ o tempo de atuação em PROEJA/EJA varia de 6 meses a um ano e sete meses. A equipe docente masculina tem entre $23 \mathrm{e}$ 67 anos, sendo que metade tem menos de 30 anos de idade e o tempo de atuação no PROEJA/EJA varia de zero a cinco anos. Dois professores têm formação técnica de nível médio.

Dos 14 professores pesquisados, nove tem formação na área das licenciaturas ou pós-graduação na área educacional, representando $64,3 \%$ dos entrevistados. Aproximadamente $21 \%$ tiveram a primeira experiência no magistério atuando no PROEJA. É uma equipe jovem; $71 \%$ têm menos de 40 anos de idade, conforme demonstrado no quadro que segue:

Quadro 1: Perfil da Equipe Docente do PROEJA

\begin{tabular}{|c|c|c|c|c|c|}
\hline Gênero & Idade & Formação & $\begin{array}{l}\text { Tempo de } \\
\text { atuação no } \\
\text { Magistério }\end{array}$ & $\begin{array}{c}\text { Tempo de } \\
\text { atuação no } \\
\text { PROEJA/EJA }\end{array}$ & $\begin{array}{l}\text { Componentes } \\
\text { Curriculares } \\
\text { ministrados } \\
\text { atualmente }\end{array}$ \\
\hline \multirow{5}{*}{ Professoras } & 24 anos & Ciências Biológicas & 4 anos & $\begin{array}{c}1 \text { ano e } 7 \\
\text { meses }\end{array}$ & Biologia \\
\hline & 27 anos & Matemática & 3 anos & 1 ano & Matemática \\
\hline & 30 anos & $\begin{array}{l}\text { Arquitetura, } \\
\text { Urbanismo e } \\
\text { Engenharia de } \\
\text { Segurança do } \\
\text { Trabalho }\end{array}$ & $\begin{array}{c}1 \text { ano e } 5 \\
\text { meses }\end{array}$ & $\begin{array}{c}1 \text { ano e } 5 \\
\text { meses }\end{array}$ & $\begin{array}{l}\text { Desenho Auxiliado } \\
\text { por Computador e } \\
\text { Fundamentos da } \\
\text { Construção Civil }\end{array}$ \\
\hline & 39 anos & Especialização & 6 meses & 6 meses & Artes \\
\hline & 49 anos & $\begin{array}{l}\text { Mestrado em } \\
\text { Educação }\end{array}$ & 26 anos & 8 meses & Química \\
\hline \multirow{9}{*}{ Professores } & 23 anos & História & 5 anos & 3 anos & História \\
\hline & 24 anos & História & 2 meses & 2 meses & História \\
\hline & 28 anos & $\begin{array}{l}\text { Processamento de } \\
\text { Dados }\end{array}$ & 4 anos & 8 meses & Informática \\
\hline & 31 anos & Agronomia & 3 anos & 6 meses & Física \\
\hline & 33 anos & Geografia & 9 anos & 4 anos & Geografia \\
\hline & 35 anos & $\begin{array}{c}\text { Técnico Segurança } \\
\text { do Trabalho }\end{array}$ & 5 anos & 1 ano & $\begin{array}{l}\text { Gestão de } \\
\text { Segurança }\end{array}$ \\
\hline & 53 anos & Engenharia & 29 anos & 7 meses & Física \\
\hline & 67 anos & $\begin{array}{l}\text { Mestrado em } \\
\text { Pedagogia } \\
\text { profissional }\end{array}$ & 32 anos & 5 anos & Desenho Técnico \\
\hline & $\begin{array}{c}\text { Não } \\
\text { informou }\end{array}$ & $\begin{array}{l}\text { Especialização em } \\
\text { Língua Portuguesa }\end{array}$ & 27 anos & 6 meses & Língua Portuguesa \\
\hline
\end{tabular}

\section{Percepções da equipe docente do PROEJA}

Na segunda etapa da análise dos dados do questionário, agruparam-se as questões que envolviam as relações interpessoais entre professores e outros profissionais da educação e a avaliação da atuação do pedagogo e auto-avaliação, conforme descrito no quadro 2. 
Quadro 2: Percepções da equipe Docente do PROEJA

\begin{tabular}{|c|c|c|c|c|}
\hline $\begin{array}{r}\text { Você } \\
\text { discute algum } \\
\text { conteúdo com } \\
\text { outros } \\
\text { professores? }\end{array}$ & $\begin{array}{l}\text { Você mantém } \\
\text { diálogo com o } \\
\text { pedagogo do } \\
\text { curso? }\end{array}$ & $\begin{array}{c}\text { Como você avalia } \\
\text { a atuação do } \\
\text { pedagogo no } \\
\text { PROEJA? }\end{array}$ & $\begin{array}{c}\text { Como você avalia } \\
\text { a sua atuação no } \\
\text { PROEJA? }\end{array}$ & $\begin{array}{l}\text { Você participa de } \\
\text { algum momento de } \\
\text { reflexão sobre o } \\
\text { PROEJA com outros } \\
\text { colegas de trabalho } \\
\text { (professores, } \\
\text { coordenador, } \\
\text { pedagogo)? }\end{array}$ \\
\hline $\begin{array}{c}12 \\
\text { professores(as) } \\
\text { responderam } \\
\text { sim e } 2 \\
\text { responderam } \\
\text { não }\end{array}$ & $\begin{array}{c}12 \text { professores(as) } \\
\text { responderam sim; } \\
1 \text { respondeu que } \\
\text { pouco e } 1 \\
\text { respondeu não }\end{array}$ & $\begin{array}{l}9 \text { professores(as) } \\
\text { acham a atuação } \\
\text { do pedagogo } \\
\text { muito satisfatória } \\
\text { e } 5 \text { acharam-na } \\
\text { satisfatória }\end{array}$ & $\begin{array}{l}6 \text { professores(as) } \\
\text { avaliaram a sua } \\
\text { atuação como } \\
\text { muito satisfatória } \\
\text { e } 8 \text { professores(as) } \\
\text { responderam } \\
\text { satisfatória }\end{array}$ & $\begin{array}{l}10 \text { professores(as) } \\
\text { responderam que } \\
\text { participam e } 4 \\
\text { responderam que } \\
\text { não participam }\end{array}$ \\
\hline
\end{tabular}

Uma das questões se foca na discussão de conteúdos com outros professores: $85,7 \%$ da equipe docente responderam que sim, ou seja, 12 professores. A procura pelo pedagogo apresenta um índice significativo, $93 \%$ da equipe. Aproximadamente $57 \%$ dos professores avaliaram sua atuação no PROEJA como satisfatória e $43 \%$ a avaliaram como muito satisfatória, demonstrando que não há avaliação negativa quanto à sua própria atuação. Quanto à atuação do pedagogo, 64,3\% dos entrevistados consideram-na muito satisfatória, e os demais a avaliam como satisfatória, em conformidade com a autoavaliação.

Sobre a participação dos professores em debates e reflexões sobre o PROEJA, 71,4\% responderam que participam. Todos os que disseram que não participam são da área das licenciaturas (Física, História e Geografia). A partir dessas informações há indícios de que os conteúdos vistos por esses docentes, em componentes curriculares da área pedagógica, nos cursos de licenciatura, estão sendo suficientes para a sua atuação no PROEJA. Contudo, nas respostas analisadas, percebeu-se que, somente 14,2\% dos professores responderam que não mantêm diálogo com o pedagogo. Significa dizer que apenas a formação inicial dos professores, nos cursos de licenciaturas, não é suficiente para atender à complexidade do processo educativo. Todos os docentes da área técnica disseram participar de momentos de reflexões sobre o PROEJA. Um professor pontuou a sua participação nesses momentos coletivos: "para refletir sobre a necessidade de incentivar esses estudantes a não desistirem. Mudar a si para mudar o mundo".

O significativo índice de participação desses professores, especialmente os das áreas técnicas, em espaços de reflexões sobre o PROEJA, parece remeter a uma busca por referências de atuação, apesar de aproximadamente $43 \%$ deles avaliarem sua atuação como muito satisfatória e os demais, como satisfatória.

Na questão sobre a relevância do PROEJA na escola, 100\% dos professores pesquisados responderam ser relevante o PROEJA na instituição. Indagados sobre o porquê da relevância do programa, a maioria das respostas aponta como oportunidade para essa parcela da população, excluída do ensino regular, voltar a estudar e qualificar-se para o mercado de trabalho; ter acesso a diferentes técnicas e tecnologias; além de o Ifes cumprir o seu papel social.

\section{Motivos que levam os docentes do PROEJA procurar o Pedagogo}

Em relação aos motivos que levam os professores a recorrerem ou não ao pedagogo e que atividades acham que ele pode desensolver para ajudá-los no PROEJA, as respostas obtidas foram organizadas e analisadas a partir das três categorias gerais, descritas no quadro 3.

Quadro 3: Motivos que levam os docentes do PROEJA a procurar o pedagogo

\begin{tabular}{|c|c|c|}
\hline \multicolumn{2}{|c|}{ Categorias de análise } \\
\hline Aspectos Pedagógicos & Aspectos Subjetivos & $\begin{array}{c}\text { Aspectos } \\
\text { Operacionais }\end{array}$ \\
\hline Planejamento de aulas; interdisciplinaridade; avaliação do & Indisciplina; & Esclarecimento \\
\hline
\end{tabular}




\begin{tabular}{|c|c|c|}
\hline $\begin{array}{l}\text { aluno, relação aluno x professor; integração curricular; } \\
\text { metodologia/recursos didáticos; acompanhamento do } \\
\text { trabalho dos docentes; informação ao professor sobre a vida } \\
\text { escolar pregressa de alunos com desempenho aquém do } \\
\text { esperado; verificação de alunos com "necessidades } \\
\text { especiais" na turma; observação da conduta do professor em } \\
\text { sala de aula; levantamento das turmas e alunos com baixo } \\
\text { rendimento; relacionamento mais direto com os alunos em } \\
\text { sala de aula; promoção de palestras e reuniões com os } \\
\text { alunos sobre a importância do curso na vida deles e curso de } \\
\text { capacitação docente sobre o PROEJA. }\end{array}$ & $\begin{array}{l}\text { comportamento e } \\
\text { atitudes estranhas } \\
\text { dos alunos; } \\
\text { frequência e } \\
\text { motivação dos } \\
\text { alunos; ajuda; } \\
\text { companheirismo; } \\
\text { troca de experiências; } \\
\text { compartilhamento } \\
\text { com o professor a } \\
\text { história de vida dos } \\
\text { alunos. }\end{array}$ & $\begin{array}{l}\text { de dúvidas sobre } \\
\text { regulamentos; } \\
\text { preenchimento } \\
\text { de diários; } \\
\text { processos } \\
\text { administrativos } \\
\text { voltados às } \\
\text { atividades } \\
\text { educacionais. }\end{array}$ \\
\hline
\end{tabular}

A consolidação desses dados demonstrou que a grande maioria dos professores, no dia a dia da escola, busca o pedagogo para apoio nos aspectos pedagógicos, seguido dos aspectos subjetivos, pois acreditam que estas sejam as atribuições essenciais do pedagogo, justificando assim, sua existência na escola. A demanda deste profissional no que tange aos aspectos operacionais não foi relevante, comprovando a ideia de Pimenta (2002), quando afirma que o pedagogo contribui com os professores no trabalho de organizar diferentes modos de ensinar os diferentes conteúdos, ter conhecimento sobre os processos de aprendizagem, enfim, executar tarefas e dominar saberes pedagógicos fundamentais à prática docente.

Quando questionados como se sentem trabalhando no PROEJA, os professores deram destaque aos aspectos subjetivos da dimensão da existência humana, dos sentimentos, do prazer, do sentir-se bem, da alegria, confirmando a visão de Freire (2009, p. 142) de que "ensinar e aprender não podem dar-se fora da procura, fora da boniteza e da alegria".

\section{Análise dos resultados B: entrevistas}

Nos campi pesquisados, entrevistaram-se oito gestoras do PROEJA, a saber: uma diretora de desenvolvimento educacional; uma gerente de gestão educacional; três coordenadoras de cursos, sendo que uma delas atua também como pedagoga; e mais três pedagogas dos cursos.

A entrevista com as participantes teve como objetivo responder às questões: os desafios enfrentados nesse programa; o PROEJA na escola tem cumprido a sua função social; como está formada a equipe do PROEJA; o trabalho desenvolvido pelo pedagogo; outras atividades que o pedagogo pode desenvolver; a atuação do pedagogo no PROEJA e no ensino regular e/ou técnico; mensagem aos profissionais que atuam no PROEJA.

Para garantir o anonimato das participantes na análise das entrevistas, os campi pesquisados foram denominados de campus $A, B$ e $C$.

\section{Desafios enfrentados no PROEJA}

Nas falas das profissionais entrevistadas surgiram desafios, dentre os quais, destacam-se:

\section{Rotatividade da equipe docente}

Esse desafio surgiu em todas as entrevistas, conforme fica evidenciado na fala de uma das coordenadoras do PROEJA:

\footnotetext{
"Alguns professores se identificam e então desenvolvem um bom trabalho, nem todos fazem isso. E os substitutos que nós chamamos aqui, que são enviados, eles desenvolvem um bom trabalho... só que dois anos depois eles vão embora. E começa tudo de novo" (LÍVIA, COORDENADORA DO PROEJA/CAMPUS B).
}

\section{Evasão}

Diversos fatores podem levar à evasão, dentre eles: espaços e tempos das escolas diferentes dos espaços e tempos dos alunos; cultura escolar que desconsidera demandas específicas desse público; metodologias inadequadas; rejeição velada ou explícita aos alunos PROEJA, entre outros, conforme destaca uma das entrevistandas: 
“Nós temos uma desistência, onde um rapaz trancou a matrícula para fazer tratamento de alcoolismo; outro rapaz ficou muito tempo fora do país e retornou. Ele insistiu muito para entrar, mas a gente percebia que era uma pessoa muito inquieta e não conseguia ficar dentro da sala. Entrava e saía várias vezes, não conseguia ficar ali!" (MARTA, PEDAGOGA E COORDENADORA DO PROEJA/ CAMPUS A).

Talvez, "escutar" o que esse aluno esteja dizendo com as suas atitudes, transformando o discurso escolar em uma fala com ele (FREIRE, 2009b, p. 113), seja uma possibilidade de acolhida e de permanência do aluno na escola.

\section{Metodologia/Sistemas de Avaliação, específicas}

Outro desafio pontuado são as metodologias e os processos avaliativos adotados. A compreensão da heterogeneidade desse público pela escola é de fundamental importância, pois o contexto dos alunos PROEJA, na fala de uma coordenadora, exige:

“Para atender esse público a escola tem que se adaptar; tem que ter espaços e tempos diferenciados; metodologias diferenciadas; avaliações diferenciadas. E isso não é discutido na Instituição. [...] Nós não conseguimos conversar com o outro, e quem é esse outro? São gestores e professores da área técnica que é onde tá o nosso problema também" (RENATA, COORDENADORA PROEJA/ CAMPUS B).

Portanto, refletir sobre possibilidades de metodologias e processos avaliativos específicos é uma demanda a ser atendida pelas instituições que ofertam essa modalidade educacional.

\section{Integração curricular e interação entre equipes docentes das áreas de formação geral e das áreas técnicas}

A integração curricular e o diálogo entre as equipes da formação geral e das áreas técnicas foram destacadas como uma necessidade:

“E o desafio maior, eu vejo, que foi o processo de integração desses alunos com a área profissional. Porque eles sentem uma dificuldade muito grande quando vão pra parte profissional. Porque, a maioria dos professores da área técnica não participa da formação, dos encontros de formação continuada..." (LÚCIA, PEDAGOGA DO PROEJA/ CAMPUS B).

Na concepção de Tardif \& Lessard (2008), o trabalho docente é uma atividade interativa e ensinar é trabalhar com seres humanos, sobre seres humanos, para seres humanos. Para desenvolver esse trabalho, os professores precisam dialogar entre si, com os alunos, com os seus saberes e o dos outros, articulando-os entre si, produzindo aprendizagens significativas.

\section{Reconhecimento institucional do alunos do PROEJA}

Uma das possibilidades de fortalecimento desse programa é o reconhecimento institucional dessa modalidade educacional. É a legitimação dos direitos dos alunos, de acordo com a fala de uma das pedagogas entrevistadas: "primeiro a questão da gestão da escola dar visibilidade a esse programa na escola; dizer EXISTE PROEJA dentro do Ifes!" (TEREZA, PEDAGOGA DO PROEJA/ CAMPUS C).

É preciso incluir o aluno, criar espaços de reconhecimento público no interior da escola. O documento base do PROEJA aponta como fundamental a consolidação de uma política específica que possibilite a elevação da escolaridade com profissionalização, de forma a contribuir para a integração sociolaboral desse grande contingente de cidadãos impedidos do direito de concluir a educação básica e de ter acesso a uma formação profissional de qualidade (BRASIL, 2007, p. 11).

\section{Tempos da escola e tempos do aluno}

A organização do trabalho cotidiano no interior das escolas possui tempos diferentes dos tempos dos educandos. Esse desafio aparece com frequência, conforme evidenciado na fala de uma das entrevistadas: 
"Então eles têm 4 aulas todos os dias à noite. Não sei que tipo de trabalho poderia ser feito; que tipo de orientações os professores deveriam receber para suprir as defasagens dos alunos nesse curto espaço de tempo que eles têm. Porque de dia, eles têm que trabalhar; tomar conta de mãe doente; do filho; esse é o contexto dos alunos". (MÁRCIA, GERENTE DE GESTÃO EDUCACIONAL/ CAMPUS C).

\title{
Inclusão
}

Outro desafio que se apresenta para a escola é a existência de alunos com alguma deficiência. Nosso sistema educacional ainda não está preparado para atender, plenamente, a essas situações, ficando o atendimento a cargo dos profissionais que atuam diretamente com esses alunos, conforme exemplo citado:

\begin{abstract}
“[...] só que ele tem um problema de saúde, que inclusive aquela lente que você está vendo ali, é uma tentativa da pedagoga de fazer com que ele consiga uma condição melhor; ele já foi ao médico, já viu que não pode usar óculos, porque tem um problema de câncer de pele que tá afetando os olhos e ele tem dificuldade de enxergar; é aquela questão da inclusão, da necessidade especial" (RITA, DIRETORA DE DESENVOLVIMENTO EDUCACIONAL/ CAMPUS A).
\end{abstract}

\section{Função social PROEJA}

Outra questão investigada foi a percepção das entrevistandas sobre o cumprimento da função social do PROEJA. Nas suas falas ficaram evidentes algumas questões, tais como: novas perspectivas de atuação profissional e aumento de renda para os alunos PROEJA; processo seletivo afunilador que impede o acesso desse público; espaço escolar não estruturado para as necessidades do aluno PROEJA e evasão. Indagadas se o PROEJA está cumprindo sua função social, uma das pedagogas destaca: "Em parte, sim. Porque você vê o relato dos alunos: depois que entraram na instituição, depois que eles começaram a fazer o PROEJA, muita coisa mudou na vida deles; outras possibilidades" (LÚCIA, PEDAGOGA DO PROEJA/ CAMPUS B).

\section{Equipe do PROEJA}

Os campi pesquisados ainda não definiram equipes específicas para atuação nesse programa, conforme evidenciado nas falas de uma das entrevistandas, demonstrando, ainda, a fragilidade do PROEJA nas instituições de educação profissional investigadas:

\begin{abstract}
"Nós temos três professores efetivos envolvidos com o programa; os outros são contratados. Isso é ruim, porque o professor contratado tem uma rotatividade muito grande. Então, quando ele está preparado, já com experiência, o contrato acaba e ele sai. E você tem de recomeçar todo o processo com quem está entrando. É um desafio, o professor que trabalha com essa clientela é um tradutor, que precisa traduzir o quê aquele determinado aluno precisa. Para um professor fazer isso não é de um dia para o outro" (ELIANE, GERENTE DE GESTÃO EDUCACIONAL/ CAMPUS C).
\end{abstract}

"Não temos uma equipe específica do PROEJA; temos a equipe da escola", pontua a Diretora de Desenvolvimento Educacional - campus A. Boa parte dos docentes, ainda, não reconhece o PROEJA como um programa específico dentro da escola e, como consequência, não busca formação específica para atendimento diferenciado a esses alunos.

\section{Trabalho desenvolvido pelo pedagogo}

Em busca de resposta à pergunta diretriz desta pesquisa "Como os pedagogos que atuam no PROEJA constroem a sua identidade?", investigou-se essa atuação a partir dos olhares de outros profissionais da escola, ou seja, das coordenadoras do PROEJA, da gerente de gestão educacional, da diretora de desenvolvimento educacional e das próprias pedagogas que atuam nos cursos do PROEJA.

A diretora de desenvolvimento educacional descreveu as atividades desenvolvidas pela pedagoga assim: acompanhamento dos diários; ajuda aos professores no controle de frequência dos alunos; acompanhamento de pagamento de bolsas. Os aspectos mais evidenciados por ela foram os operacionais e os subjetivos. 
Uma das coordenadoras do PROEJA em um dos campi investigados, pontuou as atividades desenvolvidas pelas pedagogas a acolhida aos alunos ingressantes; o assessoramento aos professores e alunos; a organização dos processos avaliativos; as reuniões pedagógicas para diagnósticos de aprendizagens; o planejamento didático-pedagógico; a formação em serviço e participação em grupo de pesquisa. Os aspectos mais evidenciados aqui foram os pedagógicos que "traduzem-se como mediação entre a organização escolar e o trabalho docente de modo a garantir as condições favoráveis à consecução dos objetivos pedagógicospolíticos da educação escolar" (PIMENTA, 2002, p.148).

\section{Outras atividades que podem ser desenvolvidas pelo pedagogo}

Outra questão investigada foi a respeito de outras atividades que os pedagogos poderiam desenvolver. Em um dos campi pesquisados parece haver um trabalho integrado entre as pedagogas e a coordenadoria do PROEJA. Os desafios observados em parceria, no cotidiano escolar, foram: grande volume de atividades a serem desenvolvidas por uma equipe reduzida; definição de estratégias para envolvimento da equipe docente das áreas técnicas na formação em serviço; reflexões sobre os processos avaliativos; mobilização dos gestores da escola.

Outra atividade pontuada foi a formação em serviço da equipe docente, sob a coordenação do pedagogo, sendo esta considerada uma necessidade. Ao professor, é exigido que ele lide, ao mesmo tempo, com grupos e indivíduos com pluralidade de saberes, com respeito e cuidado em propiciar seu aprendizado; que articule os saberes trazidos pelos alunos com os seus próprios saberes; que cumpra as exigências legais da organização escolar; que, por meio da pesquisa, construa conhecimentos de forma criteriosa de modo que sejam úteis na prática; entre muitas outras tarefas (TARDIF e LESSARD, 2008). Então, cabe ao pedagogo articular esses espaços de formação em serviço de forma a contribuir com a equipe docente na efetivação de uma educação de qualidade para quaisquer públicos atendidos.

\section{CONSIDERAÇõES FINAIS}

Chegando às considerações finais, vamos à questão que nos propusemos responder com essa pesquisa: como os pedagogos que atuam no PROEJA constroem sua identidade?

Desde a década de 80 , vem-se discutindo a identidade do pedagogo que, para além da prática específica da docência, chega à função de especialista da educação, antes caracterizada e fragmentada em orientação, supervisão e administração escolar. Os estudos da professora Selma Garrido Pimenta já apontavam, em 1980, para a importância de se superar essa fragmentação do trabalho no interior da escola, uma vez que ela contribui para alienação dos profissionais.

O pedagogo tem como "objetos" de seu trabalho a equipe docente, os alunos, outros servidores, as famílias, enfim, a comunidade escolar, com sua pluralidade de saberes e precisa articular esses saberes, mediando relações e interações, respondendo às demandas trazidas por esses sujeitos. Demandas essas que dizem respeito ao processo de ensino-aprendizagem, às metodologias, aos instrumentos avaliativos e às condições socioeconômicas, entre outras.

Assim, as atividades desenvolvidas pelas pedagogas dos cursos de PROEJA, nos campi pesquisados, demonstraram a constante interação orquestrada por elas no interior da instituição, tais como: acompanhamento do trabalho dos professores e dos alunos, acompanhamento do projeto político-pedagógico, coordenação de reuniões pedagógicas intermediárias e finais, realização de eleição de líderes, planejamento didático pedagógico com os professores, acolhida aos alunos ingressantes, coordenação de processos de integração curricular, participação em espaços de formação (grupos de pesquisa, reuniões periódicas) e outras atividades (controlam frequência dos alunos, organizam diários, acompanham o pagamento de bolsas, entre outras).

A rotina de trabalho dessas profissionais é árdua; atuam na mediação entre alunos e professores, entre esses e os gestores da escola. Precisam trabalhar na organização do próprio tempo e na organização dos tempos e dos espaços escolares. Atuam na mediação entre o trabalho docente, a organização escolar e a prática social global. Segundo Pimenta (2002) os pedagogos são profissionais necessários à escola:

[...] seja nas tarefas de administração (entendida como organização racional do processo de ensino e garantia de perpetuação desse processo no sistema de ensino, de forma a consolidar projeto pedagógico-político de emancipação das camadas populares), seja nas tarefas que ajudem o(s) professor(es) no ato de ensinar, pelo conhecimento não apenas dos processos específicos de aprendizagem, mas também na articulação entre os diversos conteúdos e a busca de um projeto pedagógico-político coerente (PIMENTA, 2002, p. 151). 
Nas suas atividades diárias, os pedagogos precisam estar alerta para atender às finalidades da escola, do projeto político-pedagógico, dos componentes curriculares, dos conteúdos, do curso, articulando-os com as finalidades da educação, que precisa afinar-se com as demandas da sociedade de um modo geral. Pimenta (2002), nos diz que a escola deve transmitir os saberes da vida cotidiana, saberes tecnológicos, econômicos e jurídicos diretamente articulados com a experiência social dos educandos. Ainda, utilizar esse saber para melhor compreensão dos problemas sociais, cabendo aos professores a importante tarefa de traduzir esses saberes, entrelaçando-os de maneira dinâmica com os saberes trazidos pelos alunos, na produção de novos conhecimentos que propiciem a transformação social para uma sociedade mais justa e igualitária. Ao pedagogo, cabe o assessoramento, o apoio ao docente para que essas finalidades se efetivem.

As pedagogas apontaram dificuldades que mereceram destaque, dentre as quais o processo seletivo não focado no público específico PROEJA; o volume de atividades a serem desenvolvidas na articulação entre alunos, professores, gestores; o tratamento do projeto pedagógico; a coordenação dos espaços de formação; o tratamento de processos de integração curricular. Organizar as diversas atividades, pessoas, finalidades, concepções de educação, organização escolar para que se torne um espaço democrático constituem-se em um desafio a ser superado pelo pedagogo.

Adequar os tempos dos alunos PROEJA às regras e normas da escola são desafios rotineiros que se colocam tanto para as pedagogas como aos docentes: horário das aulas; ausência de infra-estrutura; metodologias e processos avaliativos específicos e evasão. Os tempos do pedagogo e da equipe docente são sobrecarregados de atividades, reduzindo os tempos para reflexões das práticas pedagógicas e definição de estratégias eficazes para uma efetiva aprendizagem dos alunos.

Então, diante de tantos desafios o pedagogo necessita mobilizar uma pluralidade de saberes (TARDIF, 2005) na sua prática cotidiana, entre os quais, citam-se os saberes da formação profissional - construídos pelas instituições de formação do pedagogo; os saberes disciplinares - que emergem da tradição cultural; os saberes curriculares - que advêm de programas escolares e os saberes experienciais - adquiridos no cotidiano. São os saberes experienciais que permeiam a vida diária do pedagogo e que permitem o aperfeiçoamento da prática pedagógica na escola e a busca por formação continuada que move esse profissional da educação.

Nesse sentido, uma nova identidade profissional está emergindo para os pedagogos. Surge, então, a necessidade de delinear quais os saberes necessários a serem incluídos na formação desses profissionais e que Ihe dêem condições de responder efetivamente às tarefas e aos desafios que foram citados como de sua competência dentro dos processos educativos. Trazemos, novamente, as reflexões de Pimenta (2002) no que se refere à formação do pedagogo. Para ela, são requisitos básicos:

[...] uma sólida formação de história e filosofia da educação que permita-lhe compreender os problemas atuais da educação e a educação como prática social articulada às demais. Aí a explicação clara da educação enquanto função política. Compreender a escola como instância fundamental para a emancipação das camadas populares. Mais do que compreender, espera-se que o pedagogo apresente soluções competentes. Para isso, toda a parte de instrumentação se faz necessária. Pode-se destacar a necessidade do conhecimento do processo de aprendizagem como fundamental, de modo a que se saiba articular o lógico (dos conhecimentos científicos, técnicos) com o psicológico (do ser que aprende). A instrumentação necessária caminha desde a Didática enquanto teoria da educação até os aspectos de referencial para fazer de sua profissão um instrumento de conhecimento dessa realidade e de proposição de soluções. Ao lado de uma sólida formação acadêmica é fundamental a militância política pelas associações, sindicatos, partidos etc., que possibilitará aos cidadãos o constante referencial para fazer de sua profissão um instrumento de luta (PIMENTA, 2002, p. 188-189).

A pesquisa aponta como fundamental e necessária a formação continuada, tanto dos docentes quanto do pedagogo, incluindo a articulação dos saberes desses profissionais que envolvem, segundo Tardif (2005), os da formação profissional, os da tradição pedagógica, o saber experiencial e o saber da ação pedagógica, entre outros, para a consolidação de práticas educativas que tenham como foco a emancipação humana. Entendemos que esta formação, notadamente necessária, possa ser realizada por meio da pesquisa, em cursos de pós-graduação e, também, ao longo do próprio exercício profissional, bem como em espaços intencionalizados e sistematizados de formação em serviço, articulando os saberes do fazer pedagógico com aqueles acumulados ao longo da vida.

Assim, diante da complexidade das práticas educativas nos espaços escolares, em especial as práticas educativas realizadas no PROEJA, a identidade do pedagogo é construída e reconstruída permanentemente, 
ampliando saberes que brotam da experiência e são por ela validados (TARDIF, 2005), dentro do processo dinâmico característico da educação e da própria vida, num eterno vir a ser e estar sendo.

\section{REFERÊNCIAS}

BRASIL. Decreto no 5.840 de 13 de julho de 2006. Institui, no âmbito federal, o Programa Nacional de Integração da Educação Profissional com a Educação Básica na Modalidade de Educação de Jovens e Adultos - PROEJA, e dá outras providências. Brasília, 2006.

MEC/SETEC/PROEJA. Documento Base. Programa nacional de integração da educação profissional com a educação básica na modalidade de educação de jovens e adultos: educação profissional técnica de nível médio/ensino médio. Brasília: SETEC/MEC, 2007.

CNE/CP. Resolução CNE/CP № 1, de 15 de maio de 2006. Institui Diretrizes Curriculares Nacionais para o Curso de Graduação em Pedagogia, licenciatura. Brasília. 2006.

FREIRE, Paulo. A importância do ato de ler: em três artigos que se completam. 23ạ ed. São Paulo: Cortez Editora/ Autores Associados, 1989.

FREIRE, Paulo. Pedagogia da Autonomia: Saberes Necessários à Prática Educativa. 25a ed. São Paulo: Paz e Terra/ Coleção Leitura, 2002.

FREIRE, Paulo. Pedagogia da Autonomia: saberes necessários à prática educativa. Edição especial. São Paulo: Paz e Terra, 2009.

GIL, Antonio Carlos. Métodos e Técnicas de Pesquisa Social. 4a ed. São Paulo: Atlas, 1995. 207 p.

PIMENTA, Selma Garrido (Coord). Pedagogia: ciência da educação?. 5ạ ed. São Paulo: Cortez Editora, 2006. 134 p.

PIMENTA, Selma Garrido. O pedagogo na escola pública. 4ae ed. São Paulo: Edições Loyola, 2002. 198 p.

TARDIF, Maurice. Saberes docentes e formação profissional. 5a ed. Petrópolis, RJ: Editora Vozes, 2005. 325 p.

TARDIF, Maurice; LESSARD, Claude. O Trabalho Docente: Elementos para uma teoria da docência como profissão de interações humanas. 4a ed. Petrópolis, RJ: Editora Vozes, 2008. 317 p. 